\title{
Performance Budgeting and Medium-Term Expenditure Frameworks: A Comparison in OECD Central Governments
}

\section{Caridad Martí}

To cite this article: Caridad Martí (2018): Performance Budgeting and Medium-Term Expenditure Frameworks: A Comparison in OECD Central Governments, Journal of Comparative Policy Analysis: Research and Practice, DOI: 10.1080/13876988.2018.1526492

To link to this article: https://doi.org/10.1080/13876988.2018.1526492

曲 Published online: 29 Oct 2018.

Submit your article to this journal ¿

Џ Article views: 16

View Crossmark data $₫$ 


\title{
Performance Budgeting and Medium-Term Expenditure Frameworks: A Comparison in OECD Central Governments
}

\author{
CARIDAD MARTÍ \\ Department of Accounting and Finance, University of Zaragoza, Zaragoza, Spain
}

(Received 15 August 2017; accepted 17 September 2018)

ABSTRACT Previous literature indicates that the success of performance budgeting $(P B)$ requires budget flexibility and the implementation of medium-term expenditure frameworks (MTEFs). This study focuses on the interlinkages between PB, MTEFs and budget flexibility in 34 OECD central governments. Most countries have adopted a medium-term perspective in the budget process, but budget flexibility is limited. The findings show that MTEFs, when implemented in the past, are positively associated with PB implementation. Countries which present a higher use of performance evaluations apply more intensified monitoring and public disclosure of organizational performance if ministries/agencies do not meet performance targets.

Keywords: performance budget; evaluation reports; budget flexibility; medium-term expenditure frameworks; quantitative comparative analysis; spending reviews

\section{Introduction}

Performance budgeting (PB) refers to public sector funding mechanisms which use performance information to link funding to results - outputs and/or outcomes - with the aim of improving performance (Robinson 2007). It is intended to introduce some rationality into a traditionally subjective and political decision-making process (Willoughby 2011). Three main arguments support the introduction of PB (Bischoff and Blaeschke 2016). First, it provides the informational basis that allows policy-makers to make better informed choices and direct scarce resources where they are needed most. Second, it improves political accountability. Third, it is a tool with which policy-makers can induce changes in agencies' behaviors since they compete with each other for scarce public funds.

Although PB was initially proposed in the late 1950s, it gained renewed interest under the New Public Management reforms in recent decades (Hijal-Moghrabi 2017). PB is widely advocated by the International Monetary Fund (IMF), the World Bank and the

Caridad Martí is Lecturer in the Department of Accounting and Finance at the University of Zaragoza, Spain. Her research, in particular about comparative public finance and performance measurement, has been published in various journals.

Correspondence Address: Caridad Martí Department of Accounting and Finance, University of Zaragoza, Gran Vía, 2, Zaragoza, 50005, Spain. Email: camarti@unizar.es 
Organisation for Economic Co-operation and Development (OECD) as part of the core set of modern public finance management reforms along with medium-term expenditure frameworks (MTEFs) and spending reviews (de Jong 2015). PB may be implemented to reduce public expenditure and after government changes (OECD 2008). It could also be useful if, prior to a financial crisis, it has already been implemented. Previous research (Cohen and Karatzimas 2014) has shown that PB could offer valuable information to avoid horizontal or unjustified budget cuts, to achieve better budget fund reallocations and improvements in the performance of specific operations. Changes in public budgeting, such as a shift to PB, are still under way, or their expected benefits are yet to be fully reaped and understood, while a number of unexpected and even undesired effects have arisen (Sicilia and Steccolini 2016).

Empirical research on PB to date has been mostly based on case studies or largesample studies and has shown mixed results. There is still a lack of information about the links between different budget reforms and practices. A recent literature review (Mauro et al. 2016) suggests the need to investigate further the budgetary use of performance information, the different goals of the PB reform and its results, and to use comparative approaches to study PB. This work contributes to studying the implementation of central government budgetary reforms and the interlinkages between PB, MTEFs and budget flexibility reforms in 34 OECD countries.

This study addresses the following main research question: What has been the impact of PB, MTEFs and budget flexibility reforms on budgetary policy? The following subquestions are derived: (1) to what extent are PB, MTEFs and budget flexibility reforms implemented in OECD central governments and (2) what are the interlinkages between $\mathrm{PB}, \mathrm{MTEFs}$ and budget flexibility reforms implemented in the central governments of OECD countries?

The rest of the paper is organized as follows. Sections 2 and 3 include the theoretical framework, previous research and the hypotheses. Section 4 presents the sample, variables and method. Section 5 analyzes the results. The article ends with the main conclusions and a discussion of the findings.

\section{Performance Budgeting}

Bouckaert and Halligan (2008) distinguish three levels of managing performance: performance administration (not systematic, ad hoc and not integrated), management of performance (specialized performance systems but not integrated) and performance management (comprehensive and integrated). The OECD (2008) classifies PB into three main types. Presentational PB is a non-formal approach to the development and use of performance information in negotiations between the Ministry of Finance and spending ministries. There is no expectation of a link between performance indicators and resource allocation. Performance information is used mainly for accountability purposes and outside the budget negotiation process rather than as part of it. The second type is performance-informed budgeting, in which there is no direct or mechanical link between performance (planned or actual) and funding. In this type, when performance information is used, it can be for planning and/or accountability purposes. The third type is direct $\mathrm{PB}$, which involves allocating resources based on results achieved. 
In order to study to what extent PB is implemented in central governments, we focus on the following budget practices: standardized PB frameworks, the use of different kinds of performance information in budget negotiations and the consequences of not meeting performance targets.

\subsection{Standardized PB Frameworks}

Centralized, top-down implementation implies that there is a standard PB framework in place that applies to the whole of central government plus ministries and agencies. Centralized systems may, a priori, better align performance measures with the key national objectives and priorities. One concern is that the requirements of centralized approaches can minimize flexibility in implementation (Long and Franklin 2004). It is important to provide agency program officials with ample opportunities for dialogue about the performance implications of funding allocations. A top-down approach where staff are informed about the expected levels of performance, but where they do not agree that the expected results can be achieved with the resources provided, is not likely to be successful (Joyce 2003).

Hallerberg et al. (2009) argued, in the European context, that all countries needed to centralize their budget processes because the centralization of the decision-making procedures reduces the size of the common pool resource problem, which occurs when a group that benefits from a particular type of government spending or tax exemption does not bear the full cost of such measures. Indeed, austerity and the consequences of the global financial crisis have often caused a recentralization of budgeting processes (Sicilia and Steccolini 2016).

In the decentralized or bottom-up implementation, ministries and agencies have their own budgeting frameworks. There is some previous research that argues that, in complex settings, performance management may benefit from stronger decentralization. The decentralized approach in PB suggests that performance information should be introduced into budget negotiations at the micro level rather than systematically reported in the budget document that is voted in the legislature (Van Dooren 2011). Previous research (Van Nispen and de Jong 2017) indicated, based on the OECD 2011 PB survey, that non-financial information is used less frequently at the centralized level - that is, in the budget talks between the central budget authority and line ministries - than at the decentralized level - in the budget talks between line ministries and agencies - although the difference is almost negligible.

\subsection{Use of Different Kinds of Performance Information and Consequences of Not Meeting Performance Targets}

Regarding the kinds of information which can be used in negotiations with the central budget authority, the OECD distinguishes between financial and non-financial information. Non-financial information includes operational data and performance reports, statistical information, independent performance information, performance evaluations and spending reviews. Operational data and performance reports are annual reports, business plans, organizational strategies etc. Statistical information consists of harmonized or standardized official data which allow comparisons over time across organizations. 
Performance evaluations are evaluations of policies or programs commissioned and/or conducted by the government. Spending reviews are evaluations conducted with the explicit purpose of identifying savings or funds for reallocation. They refer to the idea of the targeted cuts approach: that is, an approach to reduce public spending that promotes a strategy of non-linear cuts where there are greater cuts in certain units/areas within an organization than in others (Agasisti et al. 2015). Spending reviews are aimed at the generation of smart cuts: that is, cuts supported by evidence in order to balance the budget (Van Nispen 2016).

In the case of a poor performance of ministries/agencies, the OECD (2013) distinguishes three main types of consequences: (1) public disclosure of organizational or program performance; (2) intensified monitoring of organization and/or program; and (3) budget decreases.

\section{PB, MTEFs and Budget Flexibility}

MTEFs are defined as fiscal arrangements that allow the government to extend the horizon for fiscal policy beyond the annual budgetary calendar. They usually cover the preparation, execution and monitoring of multi-annual budget plans and contain both expenditure and revenue projections as well as the resulting budget balances (Directorate General for Economic and Financial Affairs, DG ECFIN). A longer time horizon in the budget tries to ensure that the multi-year consequences of expenditure measures are considered. MTEFs or medium-term fiscal planning has been recognized in OECD member countries as an important tool for managing public expenditure with discipline (Bastida and Benito 2007). They are generally considered an effective tool to increase the predictability of budget outcomes and optimize resource allocation. The core objectives of a MTEF are to improve control over total budget and enable a more strategic allocation of resources between competing priorities (Di Francesco and Barroso 2015). MTEFs help address the common pool resource problem of public resources (European Commission 2007, p. 152). Empirical research (Von Hagen 1992) showed, for a sample of $12 \mathrm{EU}$ countries, that a MTEF alone is not sufficient to overcome the problems of fiscal discipline for a country where budgetary procedures have structural weaknesses.

MTEFs are considered important to a successful PB. Previous research (Bleyen et al. 2016; Mussari et al. 2016) has included the time horizon of budgets as a key variable of the context of PB implementation. Successful PB requires strategic planning (preferably government-wide) to the extent that it enables decisions to be made that establish clear evidence-based direction for government programs (Hilton and Joyce 2012). Mediumterm fiscal planning facilitates performance-informed budgeting as it provides a systemic approach to resource allocation in accordance with emerging priorities and links funding to results that may take more than one year to deliver (World Bank 2010). Therefore, it is expected that:

H1: The higher the level of implementation of MTEF, the greater the impact of PB implementation.

In line with $\mathrm{PB}$, budget modernization initiatives include the relaxing of input controls by the central budget authority and giving government organizations greater flexibility 
and autonomy to improve the efficiency and effectiveness of public expenditure. Flexibility reflects how far down the hierarchy decision-making authority is devolved or decentralized from central to spending agencies and the degree of latitude within the budget rules for varying decisions about purposes, allocations and performance assessment (Di Francesco and Alford 2016). The central budget authority plays a key role in the balance between flexibility and spending control. Central budget authorities have to balance the critical need of the government for financial discipline against the managers' need for freedom to act (Caiden 2010).

Although parliamentary appropriations usually authorize spending for one financial year, some measures of budget flexibility are: the possibility of borrowing against future appropriations and the possibility of ministers/agencies carrying over unused appropriations. The logic of allowing the carrying over of operating and investment expenditures is to eliminate the incentive for year-end spending. Otherwise, agencies/ministries, in making budget proposals, are likely to seek more than they need to cover costs and then spend the money before the end of the budget cycle to avoid losing unspent appropriations and receiving lower appropriations in the future (Moynihan 2006).

Budget flexibility is part of MTEFs. The possibility for ministers/agencies to carry over unused appropriations for operational and investment spending from one year to another is a variable of budget flexibility included in the MTEFs constructed by the OECD (2013) and by the European Commission (DG ECFIN 2015).

Previous research (Helmuth 2010) has shown that the perceived freedom of public managers has a dominant influence on perceived reform outcome. Moynihan and Pandey (2010) found that having greater flexibility, measured as the department being able to shift financial resources within its budget to accomplish its mission, increases reported performance information use. As it is likely that the greater the executive budget's flexibility, the higher the use of performance information in budget negotiations with the central budget authority, we define the following hypothesis:

H2: The greater the executive budget's flexibility, the higher the impact of PB implementation.

\section{Sample, Variables and Method}

The study is carried out using a sample of 34 OECD member countries. Table 1 includes all the variables of the study. Data were mainly taken from OECD (2013), which is based on the 2011 and 2012 OECD PB survey, and from OECD (2017), which is based on the 2016 OECD PB survey. The OECD reports extensive quality control of the responses and in-depth dialogue with member countries in order to ensure consistency and reliability. Some of these data have been used in other studies such as Van Nispen and de Jong (2017). For 20 countries of our sample which are European Union member states, we also collected data of the index on the quality of medium-term budgetary frameworks from DG ECFIN (2015) (Appendix 1).

PB systems are operationalized in this paper through the following variables: the existence of standardized PB framework for central government, the use of performance information and consequences if performance is not in line with targets. Another group of variables refers to flexibility mechanisms in budgets such as allowing ministries to 
Table 1. Description of variables

1. PB practices

PB index: Use of performance budgeting practices at the central level of government.

Existence of standardized PB framework for central government $(1=$ No, line ministries/agencies have their own; also if it is optional; $2=$ Yes)

Use of financial data in negotiations with the central budget authority (0: not applicable, information not produced or negotiations do not take place, 1 = Never; 2 = Rarely; $3=$ Occasionally; $4=$ Usually; and $5=$ Always)

Use of operational data and performance reports in negotiations with the central budget authority

(0: not applicable, information not produced or negotiations do not take place, 1 = Never; 2 = Rarely; $3=$ Occasionally; 4 = Usually; and $5=$ Always)

Use of spending reviews in negotiations with the central budget authority

(0: not applicable, information not produced or negotiations do not take place, 1 = Never; 2 = Rarely; $3=$ Occasionally; 4 = Usually; and $5=$ Always)

Use of statistical information in negotiations with the central budget authority

(0: not applicable, information not produced or negotiations do not take place, $1=$ Never; 2 = Rarely; $3=$ Occasionally; $4=$ Usually; and $5=$ Always)

Use of independent performance information in negotiations with the central budget authority

(0: not applicable, information not produced or negotiations do not take place, 1 = Never; 2 = Rarely; $3=$ Occasionally; $4=$ Usually; and $5=$ Always)

Use of performance evaluations in negotiations with the central budget authority

(0: not applicable, information not produced or negotiations do not take place, 1 = Never; 2 = Rarely; 3 = Occasionally; 4 = Usually; and $5=$ Always)

Consequences for poor performance: organizational or program's poor $\operatorname{OECD}(2013$, p. 95) performance made public

$(1$ = Never; 2 = Rarely; 3 = Occasionally; 4 = Usually; and $5=$ Always)

Consequences for poor performance: intensified monitoring of organization and/or program

OECD $(2013$, p. 95;

2017, p. 127)

OECD (2013, p. 95)

$\operatorname{OECD}(2013$, p. 95$)$

OECD (2013, p. 95)

OECD (2013, p. 95)

OECD (2013, p. 95)

OECD (2013, p. 95)

OECD (2013, p. 95)

OECD (2013, p. 95)

$(1=$ Never; 2 = Rarely; $3=$ Occasionally; $4=$ Usually and $5=$ Always)

Consequences for poor performance: budget decreases $(1=$ Never; $2=$ Rarely; 3 = Occasionally; $4=$ Usually; and $5=$ Always)

Allocation of resources for organizations (ministries and agencies) as well as programs

2. Executive budget flexibility and medium-term perspective in the budget process at the central level of government 
Table 1. (Continued)

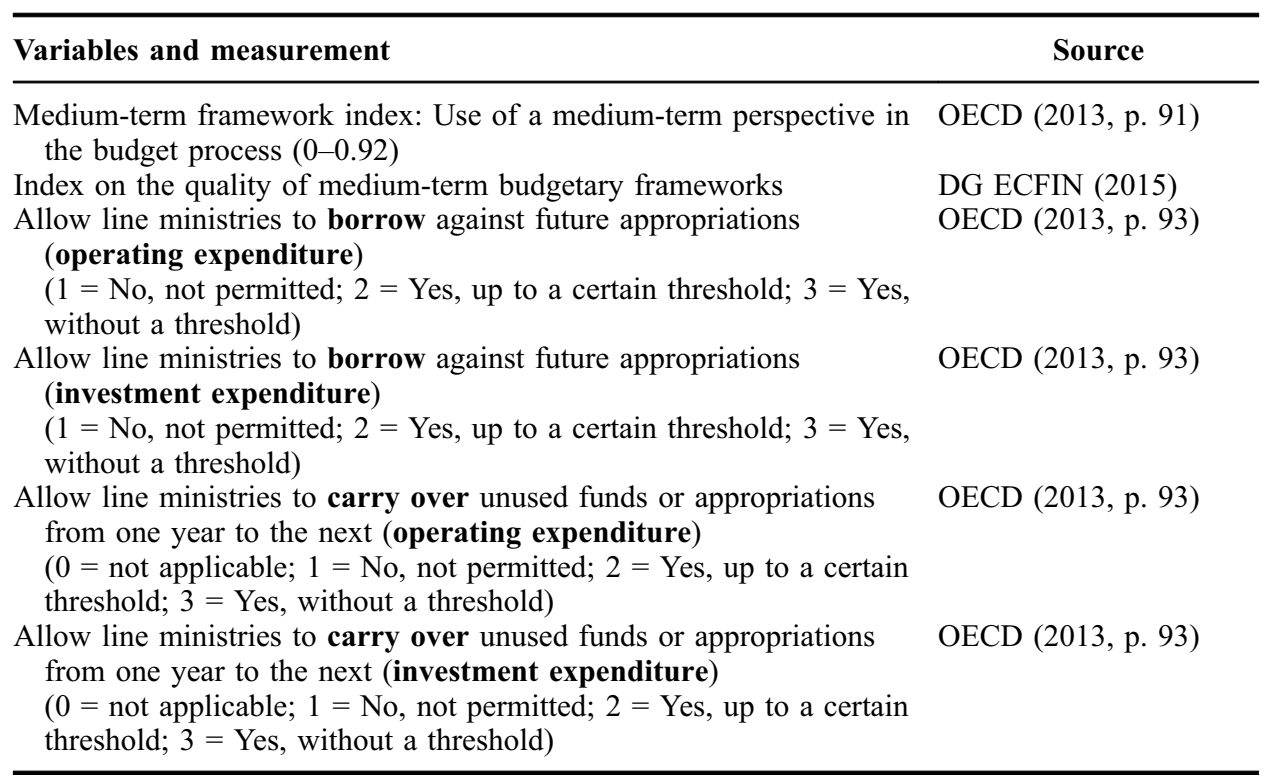

carry over unused funds and borrow against future appropriations. Furthermore, we use two indexes built by the OECD: the PB index and the MTEF index.

We start with a descriptive study of budgetary practices and procedures. We apply non-parametric ${ }^{1}$ Spearman correlations and a graphical analysis to study bi-variate relationships between budgetary reforms. ${ }^{2}$ Despite the comparative focus, the sample of 34 countries does not allow the in-depth analysis of budgetary reforms in each country.

\section{Analysis of Results}

\subsection{Descriptive Analysis}

Table 2 includes the frequencies and percentages of the answers given by the OECD countries. The majority (75 per cent) of OECD countries apply a centralized or standardized PB framework for central government. On the contrary, eight countries (Australia, Belgium, Germany, Greece, Hungary, Luxembourg, Portugal and the United Kingdom) reported that ministries/agencies have their own PB system. ${ }^{3}$

Of the different types of performance information used in negotiations with the central budget authority, "financial data" plays a predominant role in PB systems in OECD countries as it presents the highest average (4 in a range of 0 to 5) of the different forms of performance information. More than 70 per cent of the countries answered that the frequency of use of financial performance data in negotiations with the central budget authority is usually or always. The percentage is much lower for the other kinds of information. In the case of spending reviews and operational data and performance reports, 10 of the 34 countries answered that they usually or always use these two kinds of information in negotiations with the central budget authority. 


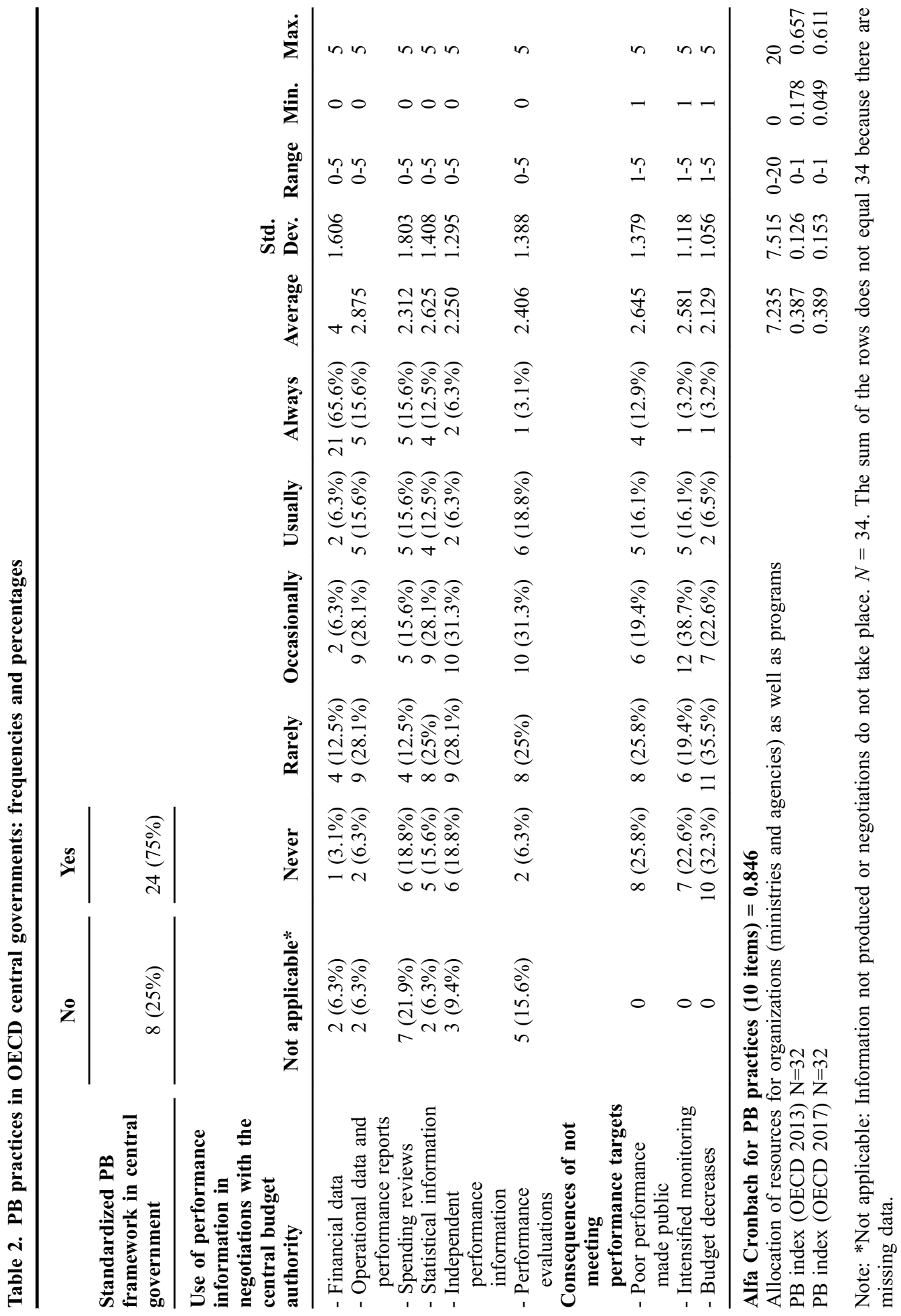


As regards the consequences of not meeting performance targets, the one most commonly applied by OECD countries, on average, is public disclosure of organizational performance (average $=2.645$ ), followed by intensified monitoring (average $=2.581$ ) and budget decreases (average $=2.129$ ), as can be seen in Table 2. If performance targets are not met by ministries/agencies, four OECD countries - Chile, Japan, Mexico and the United Kingdom - reported that they always make poor performance public and five OECD countries - Denmark, Finland, Korea, New Zealand and Slovenia - reported that they "usually" make poor performance public. Denmark ${ }^{4}$ stands out as being the only country that, on a regular basis, stipulates budget decreases if performance is not in line with targets. Finland and Korea indicated that they usually stipulate budget decreases as a consequence of poor performance. However, 10 countries indicated that they never stipulate budget decreases and 11 countries rarely stipulate them.

The findings reveal very limited executive budget flexibility in OECD countries (Table 3). In more than 85 per cent of OECD countries, ministries are not permitted to borrow operating expenditures against future appropriations. Only in Denmark, Germany, New Zealand and Sweden are ministries allowed to borrow operating expenditures against future appropriations up to a certain threshold. For investment expenditures, the countries where ministries are allowed to borrow against future appropriations up to a certain threshold are Germany, Hungary, Italy, Luxembourg, New Zealand and Sweden. A common pattern found in all the OECD countries is that there are thresholds for ministries in borrowing against future appropriations, both in the case of operating expenditure and in investment expenditure. There are more countries in which ministries are allowed to carry over unused funds or appropriations from one year to the next than countries that allow ministries to borrow against future appropriations. The flexibility to carry over appropriations is higher in investment expenditure than in operating expenditure, as can be seen in the averages of these variables: 2.152 and 1.939 , respectively. The reason is that investment expenditure often spans several years. Furthermore, the flexibility to carry over expenditure is higher than the flexibility to borrow expenditure. This may be due to the need to not exceed financial limits, controlling spending and monitoring commitments.

\subsection{Correlation Analysis}

The results of Spearman correlations provide some interesting associations (Table 4). The uses of different types of information in negotiations with central budget authorities are positively associated. The coefficients are significant and most of them are higher than 0.5. The higher the use of one kind of information, the higher the use of the other kinds of information in budget negotiations. Financial data, which is the most commonly used information in budget negotiations, is positively correlated with the use of the other five different types of performance information. Moreover, the uses of some kinds of performance information in budget negotiations are correlated with some consequences of not meeting performance targets. In particular, countries which present higher use of performance evaluations in budget negotiations apply more intensified monitoring if ministries/ agencies do not meet performance targets (coeff. $0.667^{* * *}, p$-value $=0.000$ ) as well as public disclosure of organizational performance (coeff. $0.566^{* *}, p$-value $=0.001$ ). These results highlight the importance of using performance evaluations and stipulating consequences for not meeting performance targets. As can also be seen in Table 4, the relevance of 


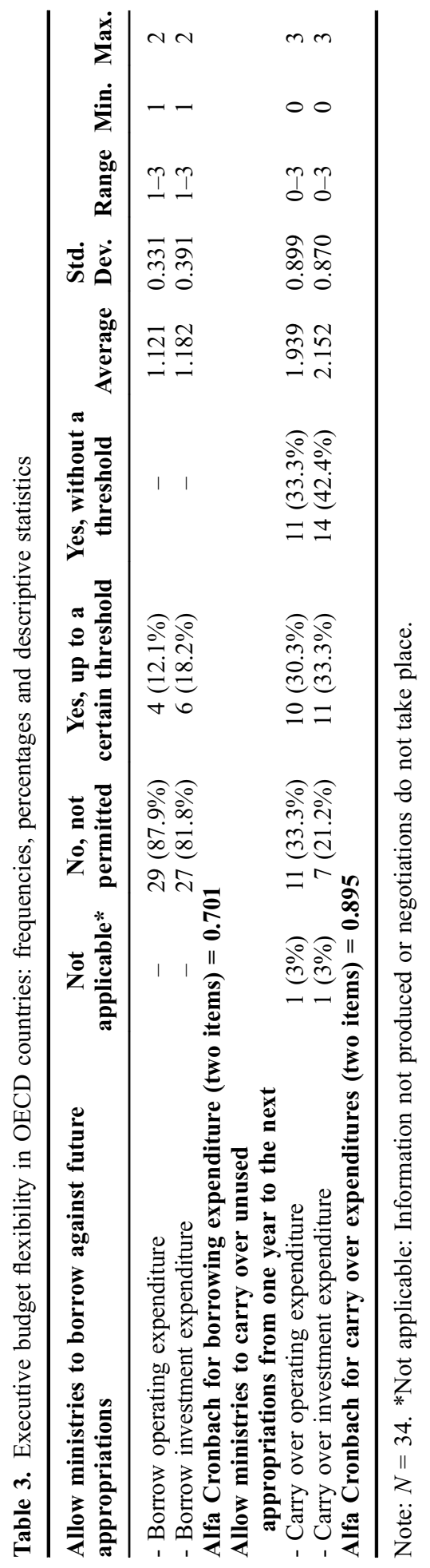




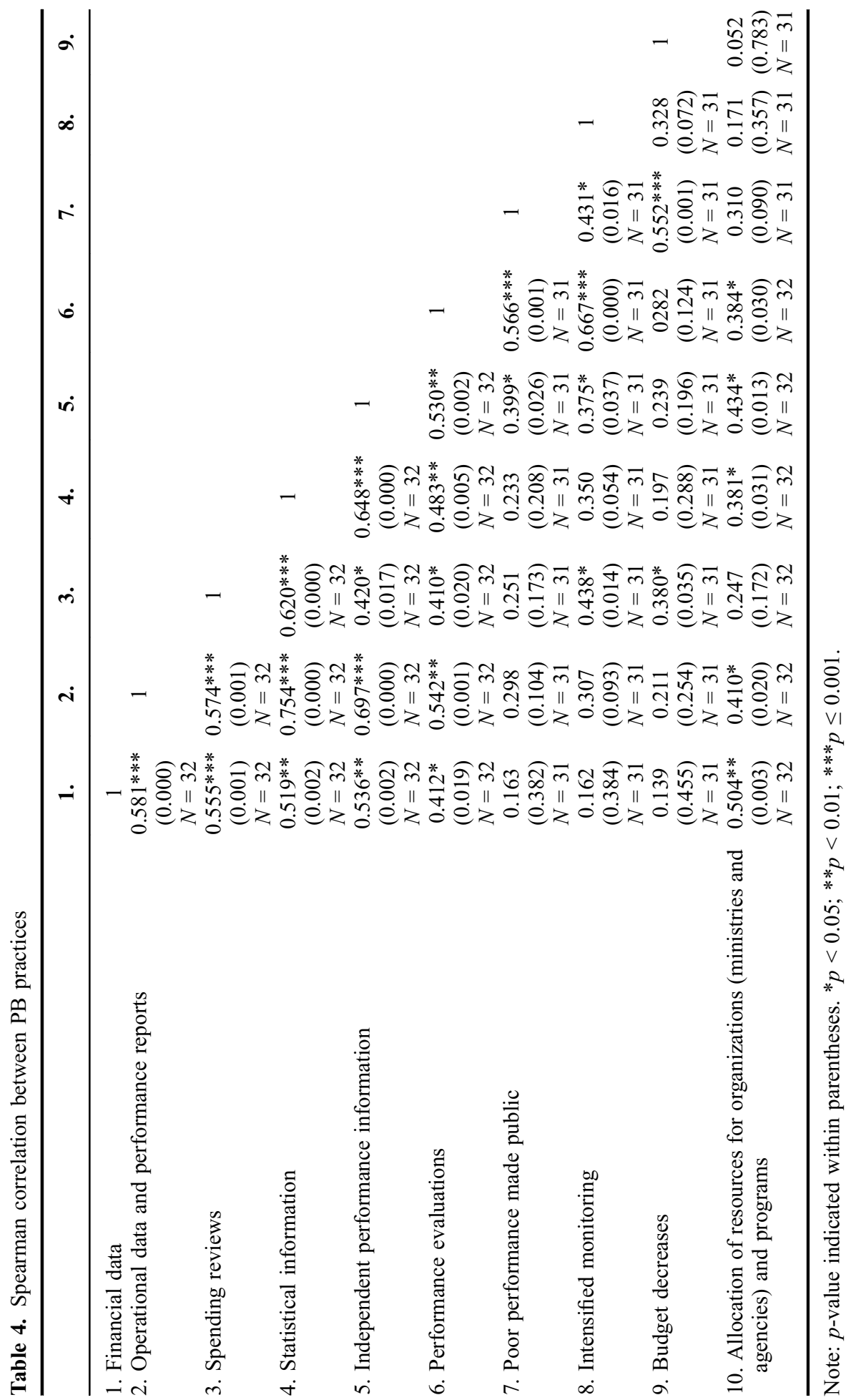


financial data is also revealed in its association with the use of performance information for allocation of resources (coeff. 0.504, $p$-value $=0.003$ ). The associations between different kinds of non-financial information - independent performance information, performance evaluations, and operational data and performance reports - and allocation of resources are not very strong and only significant at the 5 per cent level.

Table 5 presents the correlations between different budgetary reforms. The two PB indexes (2013 and 2017) are positively and significantly correlated (coeff. $=0.616, p$ value $=0.000)$. As expected, all the correlations between the PB and MTEF indexes are positive and they are somewhat higher with PB index (2017) than PB index (2013). The correlation between the PB index (OECD 2017) and the MTEF index (OECD 2013) is significant (coeff. $=0.468 ; p$-value $=0.008 ; N=31$ ). This result suggests that MTEFs, when implemented in the past, are positively associated with PB implementation. However, in the EU countries, the correlation between the PB index (OECD 2017) and the index on the quality of medium-term budgetary frameworks (DG ECFIN 2015) is not significant (coeff. $=0.360 ; N=19$ ). This might be due to the low number of countries in this correlation.

With regard to the flexibility variables, countries which allow ministries to carry over unused funds or appropriations from one year to the next for operating expenditure also allow them to carry over unused funds or appropriations for investment expenditure (coeff. $0.793^{* * *}, p$-value $=0.000$ ). In the same way, countries which allow ministries to borrow

Table 5. Correlations between PB indexes, MTEF indexes and budget flexibility variables

\begin{tabular}{lccccccc}
\hline & $\mathbf{1 .}$ & $\mathbf{2 .}$ & $\mathbf{3 .}$ & $\mathbf{4 .}$ & $\mathbf{5 .}$ & $\mathbf{6 .}$ & $\mathbf{7 .}$ \\
\hline 1.- PB index (OECD & 1 & & & & & & \\
2013) & & & & & & & \\
2.- PB index (OECD & $0.616^{* * *}$ & 1 & & & & & \\
2017) & $(0.000)$ & & & & & & \\
& $\mathrm{N}=30$ & & & & & & \\
3.- MTEF index & 0.144 & $0.468^{* *}$ & 1 & & & & \\
(OECD 2013) & $(0.433)$ & $(0.008)$ & & & & & \\
& $\mathrm{N}=32$ & $\mathrm{~N}=31$ & & & & & \\
4.- MTEF index (DG & 0.259 & 0.360 & 0.331 & 1 & & & \\
ECFIN 2015) & $(0.256)$ & $(0.130)$ & $(0.143)$ & & & & \\
& $\mathrm{N}=21$ & $\mathrm{~N}=19$ & $\mathrm{~N}=21$ & & & & \\
5.- Borrow operating & -0.020 & 0.032 & $0.381 *$ & 0.112 & 1 & & \\
expenditure & $(0.911)$ & $(0.863)$ & $(0.029)$ & $(0.627)$ & & & \\
& $\mathrm{N}=32$ & $\mathrm{~N}=31$ & $\mathrm{~N}=33$ & $\mathrm{~N}=21$ & & & \\
6.- Borrow investment & -0.225 & $-0.356^{*}$ & -0.091 & -0.018 & $0.547 * * *$ & 1 & \\
expenditure & $(0.215)$ & $(0.049)$ & $(0.615)$ & $(0.937)$ & $(0.001)$ & & \\
& $\mathrm{N}=32$ & $\mathrm{~N}=31$ & $\mathrm{~N}=33$ & $\mathrm{~N}=21$ & $\mathrm{~N}=33$ & & \\
7.- Carry over operating & 0.002 & 0.124 & 0.274 & -0.227 & 0.021 & -0.157 & 1 \\
expenditure & $(0.992)$ & $(0.506)$ & $(0.123)$ & $(0.322)$ & $(0.910)$ & $(0.384)$ & \\
& $\mathrm{N}=32$ & $\mathrm{~N}=31$ & $\mathrm{~N}=33$ & $\mathrm{~N}=21$ & $\mathrm{~N}=33$ & $\mathrm{~N}=33$ & \\
8.- Carry over & 0.004 & 0.008 & 0.036 & -0.428 & -0.088 & -0.018 & $0.793 * * *$ \\
investment & $(0.983)$ & $(0.968)$ & $(0.844)$ & $(0.053)$ & $(0.624)$ & $(0.922)$ & $(0.000)$ \\
expenditure & $\mathrm{N}=32$ & $\mathrm{~N}=31$ & $\mathrm{~N}=33$ & $\mathrm{~N}=21$ & $\mathrm{~N}=33$ & $\mathrm{~N}=33$ & $\mathrm{~N}=33$ \\
\hline
\end{tabular}

Note: pvalue indicated within parentheses. ${ }^{* * *} p \leq 0.001 ;{ }^{* *} p<0.01 ;{ }^{*} p<0.05$. 
against future appropriations for operating expenditure also allow them to borrow against future appropriations for investment expenditure (coeff. 0.547***, $p$-value $=0.001$ ). However, $\mathrm{H} 2$ is not confirmed since, as can be seen in Table 5, the correlations between the PB indexes and the budget flexibility variables are low and not significant.

The correlations between the independent variables are also non-significant except for the correlation between the MTEF index (OECD 2013) and borrowing operating expenditure which is positive (coeff. 0.381) and significant only at the 5 per cent level.

Figure $1^{5}$ shows different patterns in terms of the joint application of PB (OECD 2017) and MTEF (OECD 2013) indexes. Although OECD countries differ significantly in terms of PB and MTEFs, it can be seen that many countries score high on the two indexes. At the top right of Figure 1, there are 12 countries $^{6}$ (Austria, Canada, Denmark, Estonia, France, Finland, Korea, Slovenia, Sweden, Switzerland, the Netherlands and the United Kingdom) with higher PB and MTEF indexes than the respective OECD averages. The two lines indicate the average values of $\mathrm{PB}$ and MTEF indexes for OECD countries. The average of the $\mathrm{PB}$ index is 0.38 , with a range from 0.05 to 0.61 . The MTEF index, which can take values between zero and one, presents an average of $0.61 .^{7}$ Four countries (Belgium, Hungary, Israel and Luxembourg) reported not having MTEF and their index scores are

Figure1. PB and MTEFs in OECD countries

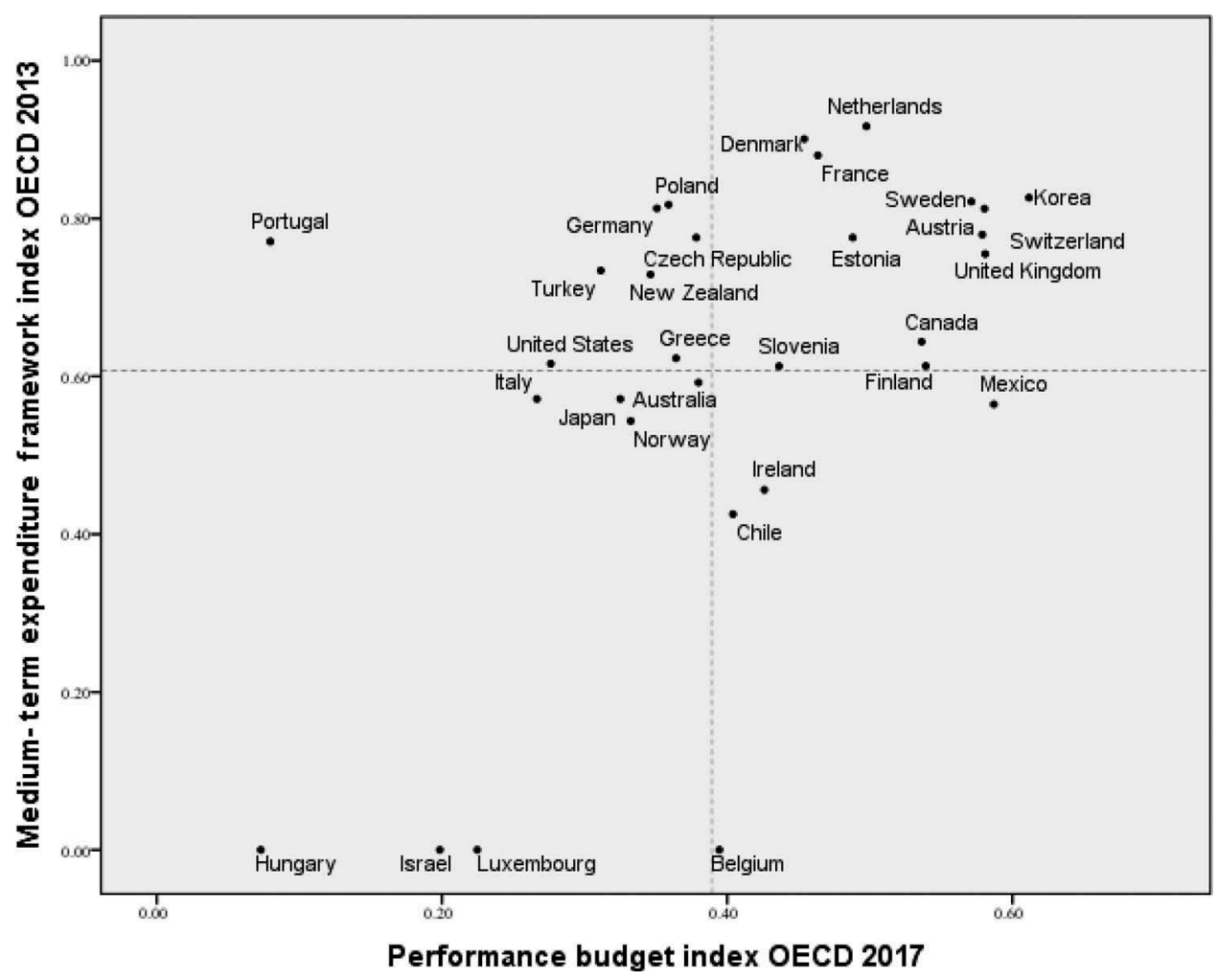


zero. Expenditure ceilings provide a top-down constraint on spending in future years and the length of these ceilings is one of the variables included in the MTEF index. In Norway and in the United States, the total aggregate expenditure ceiling spans a period of six or more years, the longest period in the OECD countries. It seems that a significant number of OECD countries have some kind of MTEF implemented and provide budget information for several years but, in many countries, there is still no link between performance results and budget appropriations and they do not stipulate budget decreases when performance targets are not met. PB procedures and practices are heterogeneous within OECD countries and there is no single best approach for all countries.

Although the evidence found in this paper is context-specific and external validity is relatively low, some of the results found are consistent with previous research conducted in other sectors such as municipalities. The research by Grossi et al. (2016, p. 597), conducted in municipalities in Germany and Italy, also shows that performance information in budgets is still mainly focused on financial and other kinds of inputs and only partly on outputs.

\section{Conclusion and Discussion}

\subsection{Interlinkages between PB, MTEFs and Budget Flexibility}

This study assesses, based on a comparative perspective, the degree of implementation of $\mathrm{PB}$ systems in the central governments of 34 OECD countries and tests whether there is an association between PB, MTEFs and executive budget flexibility reforms implemented in OECD central governments.

The majority of OECD countries apply a centralized or standardized PB framework for central government and, regarding the implementation approach, $\mathrm{PB}$ is deemed more as a top-down reform. ${ }^{8}$ Financial data has a predominant role in the use of performance information in negotiations with the central budget authority. Even though executive budget flexibility is important to a successful PB, the data reveal that, in most OECD countries, executive budget flexibility is still very limited. Very few OECD countries (Germany, Hungary, Italy, Luxembourg, New Zealand and Sweden) allow ministries to borrow investment expenditure against future appropriations and even fewer countries (Denmark, Germany, New Zealand and Sweden) allow ministries to borrow operating expenditure against future appropriations. The scant budget flexibility may be related to the fiscal crisis and limits in the deficits and debts of some OECD countries. Some recent research (Randma-Liiv and Kickert 2017) showed that the fiscal crisis did not have an instant effect of triggering structural public administration reforms or substantial shifts in existing reform trajectories in European governments. Their responses predominantly followed a combination of straightforward cutbacks and incremental change.

Furthermore, there is a need to seek an optimal balance between flexibility and control. Di Francesco and Alford (2016) proposed "responsive regulation" perspectives consisting of reshaping the types of rules and the way they are applied, rather than fewer rules, as a preferred means of enabling greater flexibility while ensuring budget control.

Despite many years of PB implementation and several PB transformations (Schick 2014), many OECD countries use different kinds of performance measures to inform but not to determine budget allocations. Denmark stands out as the only country in which budget decreases are stipulated on a regular basis if performance is not in line with targets. 
Denmark is acknowledged as one of the countries in which performance-based funding has been in place for a long time in sectors such as higher education (de Boer et al. 2015). Public disclosure of organizational performance and intensified monitoring are the types of consequences most commonly implemented by OECD countries when performance targets are not met by ministries/agencies. As pointed out by Van Nispen and de Jong (2017), the added value of adopting PB is more likely to be found in increased government transparency, support of a results-oriented culture and better enabling ex post evaluations.

There may be some possible explanations of why budget allocations are still not made on the basis of performance information in many countries, especially in the case of budget decreases. One of them is that the value of public services and/or programs cannot be measured only by performance reporting, but requires a range of other factors such as equity considerations, unmet social needs and security needs (GAO 2005). Performance information does not provide mechanistic answers for budget decisions, nor can performance data eliminate the need for considered judgment and political choice (Posner and Fantone 2007). Budgets are still largely decided by power rather than by truth (Van Nispen and de Jong 2017). The one-size-fits-all approach of PB does not recognize the uniqueness of programs or agencies (Radin 2006). Another explanation is that PB, in spite of being one of the most important reforms in budgeting within governments, has not yet achieved the headway that reformers would like (Schick 2007). It is unclear how, in the future, central governments will continue making progress in allocating resources based on reported performance in determined public services and/or programs.

\subsection{Impact of PB, MTEFs and Budget Flexibility Reforms on Budgetary Policy}

Taking the need for an integrated set of coherent budget reforms as a point of departure, we addressed the question of what the impact of budget practices has been on budget policy. The compatibility of performance systems and tools with the broader public administration framework is important because there is little evidence that a strong performance focus can coexist with an inconsistent public administration context (Bouckaert and Halligan 2008, p. 198).

The findings reveal that there are different approaches in the joint implementation of PB and MTEFs within OECD countries. Countries do not necessarily implement PB and MTEFs at the same time and to the same extent. We confirm hypothesis 1, that the higher the level of implementation of MTEFs, the greater the impact of PB. MTEFs, when implemented in the past, are positively correlated with PB implementation. As indicated in previous research (Bleyen et al. 2016; Mussari et al. 2016), the time horizon, which is a variable included in MTEFs, is also considered a key variable in the context of PB implementation.

According to hypothesis 2, it was expected that the higher the executive budget flexibility, the higher the impact of PB implementation. However, this hypothesis is not confirmed because the correlations between PB and budget flexibility are not significant. The low executive budget flexibility found may be related to the context of cutback management, budget constraints and the need to reduce public deficits and debts in many OECD countries. The experience of the recent crisis shows that allowing more flexibility in the design of the MTEF might be warranted and should be accompanied by more transparency in adjusting the budgetary targets and an increased role 
for independent monitoring of government fiscal policy and execution (Sherwood 2015).

The statistical results show that the use of financial and non-financial information in budget negotiations is related. Increasingly, non-financial information is generated, if relevant, by means other than the budget, such as program evaluations, and in times of austerity, spending reviews (Van Nispen and de Jong 2017). The correlations highlight that the use of evaluation reports in budget negotiations enables the public reporting of agencies' performance as well as the monitoring of agencies' performance. The stipulation of consequences for not meeting performance targets may incentivize positive changes in ministries/agencies' behaviors. Transparency or public disclosure of organizational performance binds agencies to particular fiscal outcomes and makes it costly for them to misbehave (Campos and Pradhan 1997). However, there could be a mixed impact of PB on public sector performance due to imperfect performance measures and window dressing activities by which agencies make their performance appear better than it is (Bischoff and Blaeschke 2016). The perversities of specific performance schemes, such as the obsession with targets, reducing the condition and ranking of an organization to a single category, and distorting the behavior of staff on the ground, need constant attention (Bouckaert and Halligan 2008, pp. 205-206).

The findings highlight the importance of using performance evaluations and stipulating consequences for not meeting performance targets. Countries which present a higher use of performance evaluations apply more intensified monitoring and public disclosure of organizational performance if ministries/agencies do not meet performance targets.

\section{Acknowledgements}

This study has been carried out with the financial support of the Spanish National R\&D Plan through research project ECO2015-66240-P and the Regional Government of Aragón-FEDER funds through research project S56_17R.

\section{Notes}

1. The Kolmogorov-Smirnov and Shapiro-Wilk tests indicated that none of the variables of the study, except for PB index (OECD 2013), PB index (OECD 2017) and MTEF (DG ECFIN 2015), have a normal distribution.

2. Multivariate analyses such as ordinary least squares regressions have been discarded because we are not assuming causal relationships.

3. We applied cross-tabulations in order to find out if there are differences between countries which apply a standardized PB framework and countries whose ministries/agencies apply their own PB, in terms of: uses of performance information, consequences of not meeting performance targets and executive budget flexibility. However, no significant differences were found.

4. In the 2016 OECD performance budgeting survey, the Czech Republic, Sweden and Denmark answered that they usually stipulate budgetary consequences if targets are not met. The questions of the 2016 OECD performance budgeting survey are not the same as in the 2012 OECD performance budgeting survey and there are many missing answers in many questions.

5. In Figure 1, 31 OECD countries are included. There is no data of the MTEF index (OECD 2013) for Iceland and there are no data of the PB index (OECD 2017) for the Slovak Republic and Spain.

6. The Netherlands and Denmark also scored high in the PB index constructed by DG ECFIN (European Commission 2007, p. 138). 
7. With the ata available for $33 \mathrm{OECD}$ countries (there is no data for Iceland) and published $y$ the OECD (2013), the arerage of the MTEF index is 0.61 . However, according to the $\operatorname{OECD~(2013,~p.~91),~therverage~}$ of the MTEF index for the OECD countries is 0.69 .

8. The stud. by Lu et al. (2015) showed, based on a review of articles between 2002 and 2011, tat PB is still deemed more as a top-down reform. On the other hand, regarding top-down and bottom-up implementation

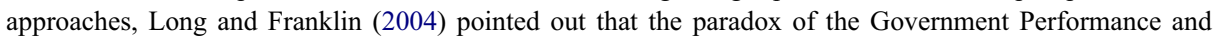

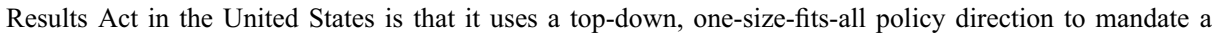

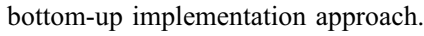

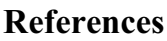

Agasisti, T., Arena, M., Catalano, G. and Erbacci, A., 2015, Defining spending reviews: A proposal for a taxonomy, with applications to Italy and the UK. Public Money and Management, 35(6), pp. 423-430.

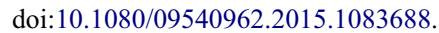

Bastida, F. and Benito, B., 2007, Central government budget practices and transparency: An international comparison. Public Administration, 85(3), pp. 667-716. doi:10.1111/padm.2007.85.issue-3.

Bischoff, I. and Blaeschke, F., 2016, Performance Budgeting: Incentives and social waste from window dressing. Journal of Public Administration: Research and Theory, 26(2), pp. 344-358. doi:10.1093/jopart/muv013.

Bleyen, P., Klimovsky, D., Bouckaert, G. and Reichard, C., 2016, Linking budget to results? Evidence about performance budgets in European municipalities based on a comparative analytical model. Public Management Review, 19(7), pp. 932-953. doi:10.1080/14719037.2016.1243837.

Bouckaert, G. and Halligan, J., 2008, Managing Performance. International Comparisons (London and New York: Routledge).

Caiden, N., 2010, Challenges confronting contemporary public budgeting: Retrospectives/prospectives from Allen Shick. Public Administration Review, 70(2), pp. 203-210. doi:10.1111/j.1540-6210.2010.02148.x.

Campos, J. E. and Pradhan, S., 1997, Evaluating public expenditure management systems: An experimental methodology with an application to the Australia and New Zealand reforms. Journal of Policy Analysis and Management, 16(3), pp. 423-445. doi:10.1002/(ISSN)1520-6688.

Cohen, S. and Karatzimas, S., 2014, Reporting performance information in the public sector: The moral behind the (non)application of program budgeting in Greece. International Review of Administrative Sciences, 80 (3), pp. 619-636. doi:10.1177/0020852313517998.

de Boer, H. F., Jongbloed, B. W. A., Benneworth, P. S., Cremonini, L., Kolster, R., Kottmann, A., LemmensKrug, K. and Vossensteyn, H., 2015, Performance-based funding and performance agreements in fourteen higher education systems. Centre for Higher Education Policy Studies (CHEPS).

de Jong, M., 2015, Why Agencies Budget for Results: exploring Institutional Explanations for Performance Budgeting: the Case of Forestry and Air Traffic Control (Amsterdam: Ipskamp Drukkers).

Di Francesco, M. and Alford, J., 2016, Balancing budget control and flexibility: The central finance agency as 'responsive regulator'. Public Management Review, 19(7), pp. 972-989. doi:10.1080/14719037.2016.1243812.

Di Francesco, M. and Barroso, R., 2015, Bottom-up costing within medium-term expenditure frameworks: A survey of Practices in Selected OECD countries. Public Budgeting and Finance, 35(3), pp. 44-67. doi: $10.1111 /$ pbaf.12069.

Directorate General for Economic and Financial Affairs (DG ECFIN), 2015 European Commission. https://ec. europa.eu/info/business-economy-euro/indicators-statistics/economic-databases/fiscal-governance-eu-mem ber-states/medium-term-budgetary-framework_en

European Commission, 2007, European Economy, Directorate-General for Economic and Financial Affairs, $\mathrm{N}^{\circ} 3$. Grossi, G., Reichard, C. and Ruggiero, P., 2016, Appropriateness and use of performance information in the budgeting process: Some experiences from German and Italian municipalities. Public Performance and Management Review, 39(3), pp. 581-606. doi:10.1080/15309576.2015.1137770.

Hallerberg, M., Rainer Strauch, R. and Von Hagen, J., 2009, Fiscal Governance in Europe (Cambridge: Cambridge University Press).

Helmuth, U., 2010, Better performance with performance budgeting? Analyzing cases of success and failure in public administrations. International Public Management Journal, 13(4), pp. 408-428. doi:10.1080/ 10967494.2010.524833. 
Hijal-Moghrabi, I., 2017, The current practice of Performance-based Budgeting in the Largest U.S. Cities: An Innovation theory perspective. Public Performance and Management Review, 40(4), pp. 652-675. doi:10.1080/15309576.2017.1313168.

Hilton, R. M. and Joyce, P., 2012, Performance-informed budgeting: A global reform, in: B. Guy Peters and J. Pierre (Eds) Handbook of Public Administration (London: Sage), pp. 480-495.

Joyce, P. G., 2003, Linking Performance and Budgeting: opportunities in the Federal Budget Process (Washington, D.C.: IBM Centre on the Business of Government).

Long, E. and Franklin, A. L., 2004, The paradox of implementing the Government Performance and Results Act: Top-Down direction for Bottom-Up implementation. Public Administration Review, 64(3), pp. 309-319. doi:10.1111/puar.2004.64.issue-3.

Lu, E. Y., Mohr, Z. and Ho, A., 2015, Taking stock: Assessing and improving performance budgeting theory and practice. Public Performance and Management Review, 38(3), pp. 426-458. doi:10.1080/15309576.2015.1006470.

Mauro, S. G., Cinquini, L. and Grossi, G., 2016, Insights into performance-based budgeting in the public sector: A literature review and a research agenda. Public Management Review, 19(7), pp. 911-931. doi:10.1080/14719037.2016.1243810.

Moynihan, D. and Pandey, S., 2010, The big question for performance management: Why do managers use performance information? Journal of Public Administration: Research and Theory, 20, pp. 849-866. doi:10.1093/jopart/muq004.

Moynihan, D. P., 2006, Managing for results in State Government: Evaluating a Decade of Reform. Public Administration Review, 66(1), pp. 77-89. doi:10.1111/puar.2006.66.issue-1.

Mussari., R., Tranfaglia, A. E., Reichard, C., Bjørnå, H., Nakrošis, V. and Bankauskaitè-Grigaliūnienė, S., 2016, Design, Trajectories of Reform and Implementation of Performance Budgeting in Local Governments: A Comparative Study of Germany, Italy, Lithuania and Norway, in: S. Kuhlmann and G. Bouckaert (Eds) Local Public Sector Reforms in Times of Crisis. National Trajectories and International Comparisons (New York: Palgrave Macmillan), pp. 101-120.

OECD, 2008, Performance Budgeting: A User's Guide (Paris: OECD).

OECD, 2011, International performance budgeting database (Paris: OECD). https://qdd.oecd.org/subject.aspx? Subject $=593 \mathrm{~d} 28 \mathrm{f} 2-6 \mathrm{f} 88-4 \mathrm{dd} 1-\mathrm{b} 59 \mathrm{e}-\mathrm{f} 997 \mathrm{c} 3 \mathrm{~b} 34 \mathrm{c} 6 \mathrm{e}$

OECD, 2013, Government at a Glance (Paris: OECD).

OECD, 2017, Government at a Glance (Paris: OECD).

Posner, P. L. and Fantone, D. F., 2007, Assessing federal program performance. Observations on the U.S. Office of Management and Budget's Program Assessment Rating Tool and its use in the budget process. Public Performance and Management Review, 30(3), pp. 351-368. doi:10.2753/PMR1530-9576300303.

Radin, B. A., 2006, Challenging the Performance Movement (Washington, DC: Georgetown University Press). Randma-Liiv, T. and Kickert, W., 2017, The impact of the fiscal crisis on public administration reforms: Comparison of 14 European countries. Journal of Comparative Policy Analysis: Research and Practice, 19 (2), pp. 155-172. doi:10.1080/13876988.2015.1129737.

Robinson, M. ed, 2007, Performance Budgeting: linking Funding to Results (Basingstoke and New York: Palgrave Macmillan/IMF).

Schick, A., 2007, Performance Budgeting and Accrual Budgeting: Decision rules or analytic tools? OECD Journal on Budgeting, 7(2), pp. 109-138. doi:10.1787/budget-v7-2-en.

Schick, A., 2014, The metamorphoses of Performance Budgeting. OECD Journal on Budgeting, 13(2), pp. 4979. doi:10.1787/16812336.

Sherwood, M., 2015, Medium-term budgetary frameworks in the EU member states. European Commission, Directorate General for Economic and Financial Affairs. Discussion Paper 021. Luxemburg: Publications Office of the European Union.

Sicilia, M and Steccolini, I, 2016, Public budgeting in search for an identity: State of the art and future challenges. Public Management Review, pp. 1-6. doi:10.1080/14719037.2016.1243809.

U.S. Government Accountability Office, 2005, 21st century challenges: Performance Budgeting could help promote necessary reexamination. (GAO-05-709T). Washington DC: U.S.

Van Dooren, W., 2011, Better Performance Management: Some Single and Double-Loop Strategies. Public Performance and Management Review, 34(3), pp. 420-433. doi:10.2753/PMR1530-9576340305.

Van Nispen, F. K. M., 2016, Policy Analysis in Times of Austerity: A cross-national comparison of Spending Reviews. Journal of Comparative Policy Analysis: Research and Practice, 18/5, pp. 479-501. doi:10.1080/ 13876988.2015.1005929. 
Van Nispen, F. K. M. and de Jong, M., 2017, Evidence-based budgetary policy: Speaking truth to power?, in: M. Brans, I. G. May and M. Holett (Eds) Routledge Handbook of Comparative Policy Analysis (New York/ Abingdon: Routledge), pp. 143-165.

Von Hagen, J., 1992, Budgeting procedures and fiscal performance in the European Communities, European Economy, Economic Paper, No. 96.

Willoughby, K., 2011, Introduction to the symposium: PBB- Works like the BCS? Public Administration Review, 71(3), pp. 352-355. doi:10.1111/puar.2011.71.issue-3.

World Bank, 2010, Results, Performance Budgeting and Trust in Government (Washington DC: The International Bank for Reconstruction and Development/The World Bank).

\section{Appendix}

Table A1. Indexes

\begin{tabular}{|c|c|}
\hline Index & Definition and composition \\
\hline $\begin{array}{l}\text { Use of a PB system } \\
\text { Sources: OECD (2013, pp. } \\
\text { 175-177) and OECD }(2017 \text {, } \\
\text { p. 127). }\end{array}$ & $\begin{array}{l}\text { The PB index is a composite index that contains } 11 \text { variables } \\
\text { (2013) and } 10 \text { variables }(2017) \text {. The weightings for the broad } \\
\text { categories are as follows: } \\
\text { 1) Availability of performance information }(65 \%) \text {. } \\
\text { 2) Utilization of performance information in the budget } \\
\text { negotiations }(20 \%) \text {. } \\
\text { 3) Sanctions in case of not achieving the targets }(15 \%) \text {. }\end{array}$ \\
\hline $\begin{array}{l}\text { Use of a medium-term } \\
\text { perspective in the budget } \\
\text { process } \\
\text { Source: OECD }(2013, \mathrm{pp} \text {. } \\
175-177) \text {. }\end{array}$ & $\begin{array}{l}\text { The MTEF index measures the extent to which countries have } \\
\text { developed a medium-term perspective in their budget process, } \\
\text { but it does not evaluate whether this perspective has been } \\
\text { effective in achieving budget outcomes. } \\
\text { It contains } 10 \text { variables grouped into four characteristics. The } \\
\text { weightings for the broad categories are as follows: } \\
\text { 1) Existence of a MTEF and legal/policy basis of it }(25 \%) \text {. } \\
\text { 2) Length, levels and substance of the ceilings }(33.33 \%) \text {. } \\
\text { 3) Quality and durability of the ceiling }(25 \%) \text {. } \\
\text { 4) Monitoring of the MTEF }(16.67 \%) \text {. }\end{array}$ \\
\hline $\begin{array}{l}\text { Index on the quality of } \\
\text { medium-term budgetary } \\
\text { frameworks } \\
\text { Source: DG ECFIN (2015) } \\
\text { https://ec.europa.eu/info/ } \\
\text { business-economy-euro/indi } \\
\text { cators-statistics/economic- } \\
\text { databases/fiscal-governance- } \\
\text { eu-member-states/medium- } \\
\text { term-budgetary-framework_ } \\
\text { en }\end{array}$ & $\begin{array}{l}\text { This index includes five dimensions: } \\
\text { 1) the existence of a domestic MTEF; } \\
\text { 2) the connectedness between the multi-annual budgetary } \\
\text { targets and the preparation of the annual budget; } \\
\text { 3) the involvement of national parliaments in the preparation of } \\
\text { medium-term budgetary plans; } \\
\text { 4) the existence of coordination mechanisms between subsector } \\
\text { of general government prior to setting the medium-term } \\
\text { budgetary targets; } \\
\text { 5) the monitoring and enforcement mechanisms of multi-annual } \\
\text { budgetary targets. }\end{array}$ \\
\hline
\end{tabular}

Note: These composite indexes vary from 0 to 1 . 